\title{
Leadership challenges experienced by elite South African rugby coaches
}

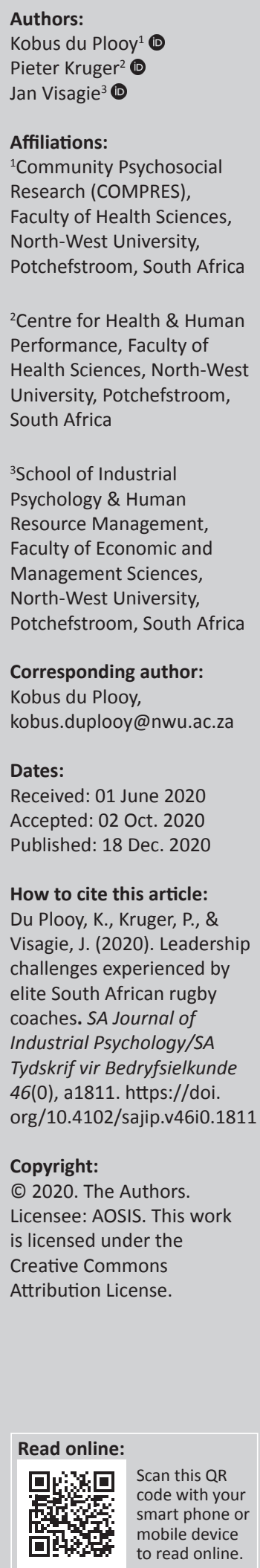

Orientation: As the leaders of teams that compete at the highest level, elite South African rugby coaches face constant pressures to consistently lead their teams to successful on-field performances. An understanding of the leadership challenges they face may highlight actions that could equip them to achieve this more effectively.

Research purpose: To investigate the leadership challenges experienced by the head coaches of elite South African rugby teams that compete on an international level.

Motivation for the study: The leadership challenges faced by elite South African coaches could become clearly known only through investigation, and subsequently they could be properly addressed.

Research approach/design and method: A qualitative approach with a phenomenological design was utilised, which collected data by means of in-depth interviews with the head coaches of elite South African rugby teams. Eleven teams were considered to be elite South African rugby teams for this study given that they competed on an international level. Ultimately, six participants were included, representing $54.5 \%$ of the total population. The general systems theory was also used as a theoretical basis to present findings.

Main findings: The data revealed three main themes, namely environmental, relationships and personal leadership challenges. The data revealed that these coaches experience significant leadership challenges, some of which are unique to the South African context.

Practical/managerial implications: It is believed that the implementation of suggested recommendations will assist in ensuring both the economic survival and overall leadership improvement of coaches and the teams they lead.

Contribution/value add: Theoretically the study added to the limited literature on leadership in elite South African sport and practically it provided recommendations to address the findings as well as for further research.

Keywords: leadership; challenges; rugby; coaches; elite sport; elite rugby coaches; South African rugby; general systems theory; phenomenology.

\section{Introduction}

\section{Orientation}

The sport of rugby union (referred to as 'rugby') has experienced significant growth since becoming a professional sport in 1995 as between 400000 and 500000 players of all racial groups and both sexes were playing rugby in South Africa by 2011 (Brown et al., 2012). Simultaneously, this also led to growth in the business of rugby. The link between performance and business in elite sports has been well researched and documented in recent years (Cruickshank \& Collins, 2012). This also held true for rugby as it was indicated in the 2016 annual report by World Rugby, the sport's international governing body, that the 2015 Rugby World Cup generated a surplus of $€ 163$ million in revenues for World Rugby alone (World Rugby Year in Review, 2016). This amounted to a 78\% increase when compared to the previous rugby world cup in 2011. This had also led to an increasing focus on the performances of professional teams as the revenues generated by teams (e.g. from television broadcasting rights, ticket and merchandise sales) are often positively correlated to their on-field performances (Carmichael, McHale, \& Thomas, 2010; Morgan, 2002). As leaders of these teams, it has also highlighted the critical importance and pressures on their head coaches to facilitate successful on-field performances (Roberts, 2013). 


\section{Research purpose and objective}

Given the critical importance of leadership in elite sport (Fletcher \& Arnold, 2011), the single objective of the present study was to obtain an understanding of what leadership challenges elite South African rugby coaches were experiencing. To avoid speculation, the researchers sought to determine this by interviewing these coaches themselves. The study focused specifically on elite teams as it was also assumed that it is at the elite level where the economic impact of these challenges is most felt. It was believed that understating these challenges may not only facilitate a clearer understanding of them, but such an understanding may also highlight actions that could be taken to potentially address or at least ameliorate them. Furthermore, scholars such as Greenwood, Davids and Renshaw (2012), as well as Williams and Kendall (2007), have called for increased empirical research on the knowledge and experiences of elite coaches as they argued that this is critical to further enhance empirical research on sporting performance and leadership.

\section{Literature review}

Effective leadership is sought after in almost all types of industries around the globe, including elite sport. This is because, amongst other factors, it has been found to be a stronger predictor of promotion than intellectual ability (Germain, 2012). Much debate, however, continues to rage in the literature regarding the actual definition of leadership, to the extent that some authors such as Jian and Fairhurst (2017) had adopted the position of not defining the concept at all given its complexity and how it may differ between contexts. Yukl (2012) further explained that most definitions of leadership viewed it as a process where influence was purposefully being exerted over individuals with the aim of guiding, structuring and facilitating activities as well as relationships within a particular group or organisation. For the purpose of the present study, the following definition of leadership by Woods and West (2016) was, however, adopted for its simplicity: 'A specialised role that an individual occupies and the process of influence' (p. 381).

When considering what leadership style is best suited for the challenges coaches face in elite rugby, a study by Hodge, Henry and Smith (2014) revealed the transformational leadership style which had been implemented by the coaches of the New Zealand All Blacks (New Zealand national rugby side) had been instrumental to their success in winning the 2011 Rugby World Cup. As such, transformational leadership is regarded as the most effective leadership style to be adopted by elite rugby coaches. This may be as, according to Avolio and Yammarino (2002), transformational leadership was conceptualised as containing four behavioural components, namely idealised influence, inspirational motivation, intellectual stimulation and individualised consideration. In accordance with these characteristics, transformational leaders can be characterised, amongst others, as people who are open to new suggestions, are effective communicators, set clear expectations as well as empower those whom they lead by creating new learning opportunities for them. All of these appear to be critical to elite rugby coaches as the continued success of the All Blacks have underscored. Furthermore, application of this type of leadership style has also been found to be effective within other elite sport codes, for example, Hamza and Abdelmonem (2018) had found it to have increased employee empowerment amongst a number of Egyptian sporting codes. As such, transformational leadership appears to be the best suited leadership style to be utilised by coaches at the elite level, including rugby.

When investigating the leadership challenges specifically experienced by elite South African rugby coaches, no studies could be identified from the literature. A challenge was further defined as 'the situation of being faced with something that needs great mental or physical effort in order to be performed successfully and therefore tests a person's ability' (Challenge, 2018) for the purpose of the present study. From this perspective, challenges include all aspects that may either directly or indirectly impede an elite coach from executing his or her role effectively, ranging from frustrations stemming from sources outside his or her direct influence to factors directly causing hindrances stemming from areas within his or her immediate sphere of influence.

One of the studies that were identified from the literature which had investigated leadership challenges experienced by elite coaches from rugby and other sporting codes, was conducted in the United Kingdom by Thelwell, Weston and Greenless (2010), who interviewed three elite sports coaches to examine the stresses they were experiencing and the coping strategies they employed to cope with them. The sample included an elite soccer, cricket and rugby coach, respectively. All of the coaches referred to performance stressors to relate to poor on-field performances of their teams. Another related United Kingdom-based study by Arnold, Fletcher and Molyneux (2012) investigated performance leadership and management in elite sport amongst 13 national performance directors of Olympic sports. The study made use of a qualitative approach by means of individual interviews. Results identified four main themes of challenges, namely vision, operations, people and culture. A study by Orlowski, Wicker and Breuer (2016) investigated which challenges may have contributed towards the probability that elite German sports coaches would have vacated their positions. It included a sample of 1860 coaches from 45 different sporting codes and results of a regression analysis indicated that higher income, contracts of longer duration, responsibility for personnel and being able to speak the required language significantly increased the probability that a coach would accept a new position, whilst distances of nine flight hours and more, lower reputation of the position and career perspectives reduced it.

In a South African study, Surujlal and Mafini (2011) investigated the reasons why coaches left their positions as well as what challenges they faced. The study investigated 
the management of professional sports coaches in organisations affiliated with the South African Sports Confederation and Olympic Committee (SASCOC). Results revealed recruitment and selection, training and development, compensation, and job security to be lacking and requiring improvement when it came to the management of elite South African sports coaches. The authors further noted that demographic changes, workforce diversity, changing managerial and coaching skills requirements and government legislation were all unique aspects of the South African sporting context that were also changing the very nature of sports organisations in the country. As such, they warned that if these human resourcerelated challenges of elite South African sports coaches were not addressed, it could lead to them leaving their positions. Another South African study by Pelser-Carstens, Keyser and Surujlal (2015) also investigated the reasons why elite South African coaches resigned from their positions. The findings of this study included that increased workload and anxiety have the potential to influence coaches' intentions to resign. Furthermore, no studies could be found that had specifically focused on the leadership challenges experienced by elite South African rugby coaches.

\section{Research design \\ Research approach}

In view of the limited knowledge available of leadership challenges in elite sport, this study was deemed best suited for a qualitative research approach as, according to Creswell (2009), qualitative research methods often take on an exploratory approach, whereby it seeks to understand participants' unique subjective views of their worlds. The present study, therefore, utilised this approach as it was both explorative and descriptive in nature.

\section{Research method}

The researchers made use of a phenomenological research design. This design was deemed the most suitable as it explicates a thorough understanding of participants' lived experiences (Creswell, 2009; Fouché \& Schurink, 2011).

\section{Data collection method}

In-depth unstructured interviews were used to collect the data, which posed one primary open-ended question to the participants, namely: 'Please tell me what leadership challenges you currently experience as an elite South African rugby coach?' Further probing questions were also asked where participants did not spontaneously elaborate on their answer to the primary research question.

\section{Data recording}

A recording of each interview was made with a recording device. These interviews ranged between 18:03 and 25:17 min at an average of 20:21 min per interview.

\section{Research setting}

All interviews were conducted telephonically at a date and time that suited the participants to conduct the interview in a private setting.

\section{Research participants and sampling methods}

For this study, an elite South African rugby team was regarded to be a South African rugby team that competed on an international level. These included only the following 11 teams: the Springboks (South African senior national team); U/20 Springboks; U/19 Springboks; Springbok Men's Sevens; Springbok Women's Sevens along with the Super Rugby sides Bulls, Sharks, Stormers and Lions; and the Pro 14 sides Kings and Cheetahs. Furthermore, an elite South African rugby coach was viewed as the head coach of any of the aforementioned teams for this research project. Purposive sampling was used to identify and recruit participants. This approach is frequently utilised when there is a limited number of potential participants who possess the experience or expertise pertaining to the topic under investigation as was the case in this project (Devers \& Frankel, 2000).

\section{Entrée and establishing researcher roles}

Recruitment was performed with the assistance of the second author who already held existing relationships with a number of the participants, which had emanated from his work in the elite sports domain. He briefly introduced the topic and procedure to the potential participants. Only coaches who agreed to participate and completed the informed consent forms were then contacted for an interview. Amongst the head coaches of the aforementioned 11 teams, 6 agreed to participate in the study, representing $54.5 \%$ of the total population. This was regarded to be a suitable representation of the total population and saturation of the data was therefore determined by this maximum number of participants who participated (Mason, 2010).

\section{Strategies employed to ensure data quality and integrity}

Participants voluntarily partook in the study and had to sign an informed consent form on which confidentiality and anonymity were also ensured. Given the potential sensitive nature of the topic and the fact that the coaches are well known by the public, special care was taken not to reveal their identities at any time. Furthermore, the model of Lincoln and Guba was used to ensure the trustworthiness of this study and therefore a consistent focus on credibility, dependability, conformability and transferability throughout the study (Krefting, 1991).

\section{Theory base}

The general systems theory (GST), as first postulated by the biologist Ludwig Von Bertalanffy (1972), was selected 
to serve as the theoretical base for the present study. According to this theory, individuals form part of interlocking systems, for example, the individual, the family, the organisation and the community (Goldberg \& Goldberg, 2008). Within this framework the coaches were seen to form part of various systems that all mutually interacted with and influenced each other. As such, a change made to one part of these systems would inadvertently affect all the other parts. For this reason, the GST was regarded to be particularly suitable established theoretical framework from which to present the results of the present study. This was as the three themes and their respective sub-themes that emerged from the data could be naturally grouped into three interlocking systemic domains, namely the environmental, relationships and personal domains. Each of these domains is constantly influencing and interacting with others.

\section{Data analysis}

Thematic analysis was used for analysing the data in the present study and the steps proposed by Braun and Clarke (2006) served as the primary guide for this purpose. These steps included familiarisation, generating initial codes, grouping codes according to similarity, reviewing of themes, defining and naming of themes and composing the final report.

\section{Reporting style}

Results are reported next in Figure 1 that provides an overview of the findings as integrated with the GST.

\section{Ethical consideration}

The research was approved by the Economic and Management Sciences Research Ethics Committee (EMS-REC) of the North-West University: EMS-REC NWU-00316-18-A4.

\section{Results}

\section{The environmental domain}

This supra-system included environmental challenges that fell outside of the immediate sphere of influence of the coaches, but which presented challenges to their leadership. This included the first theme that emerged from the data, namely environmental leadership challenges. This theme included various sub-themes, the first of which were challenges that coaches experienced in relation to South African Rugby Union (SARU), the governing body of rugby in South Africa.

The first aspect that emerged as part of this sub-theme was general dissatisfaction with slow decision-making processes

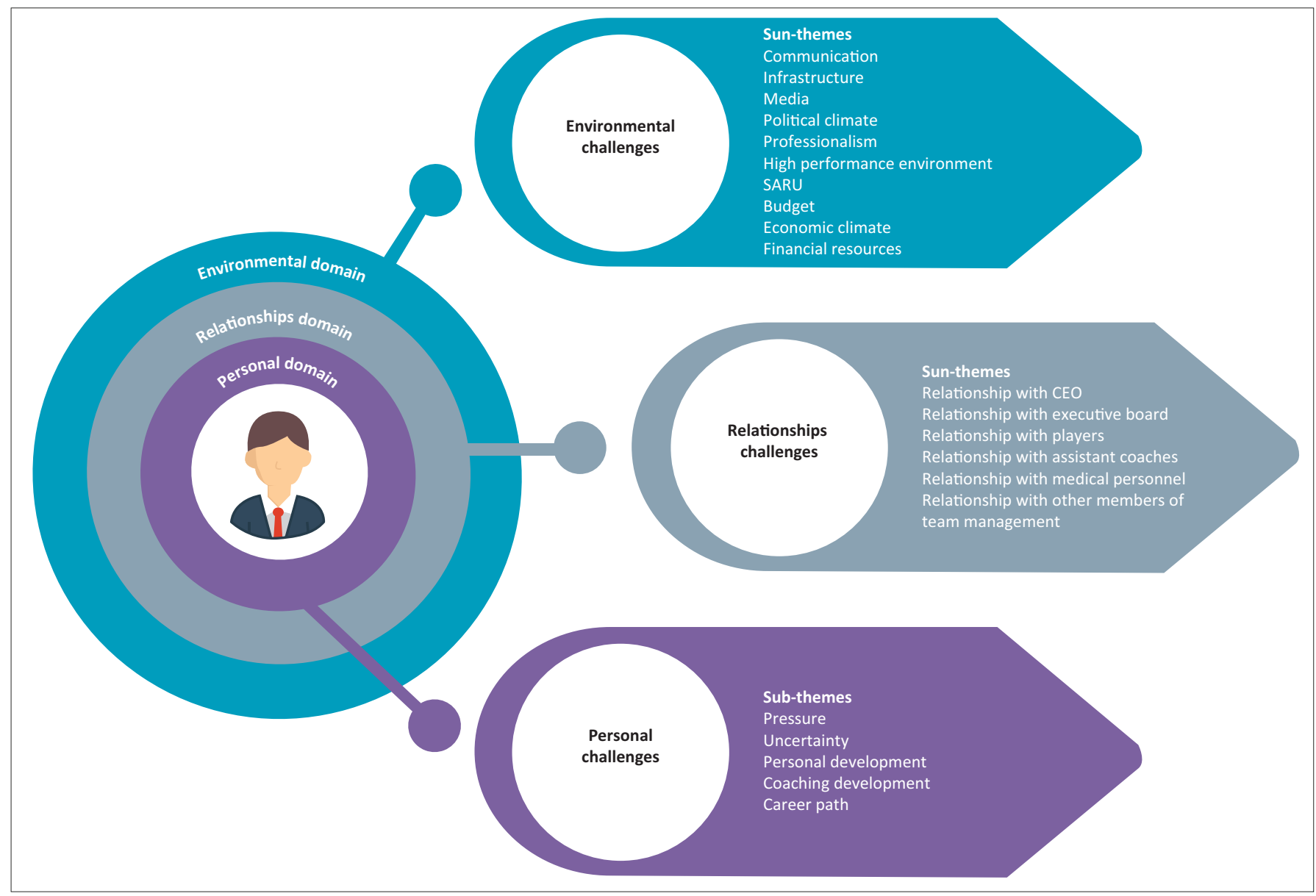

Source: Du Plooy, K. (2019). Leadership challenges experienced by elite South African rugby coaches, Master's dissertation, North-West University, Potchefstroom FIGURE 1: Leadership challenges experienced by elite South African rugby coaches. 
and the ineffective communication coaches experienced from SARU. Participant 3 indicated that:

'... we don't have a centralised system where all communication from SARU comes from like the All Blacks and Ireland have'. (P3, Head Coach, July 2018)

Decision-making, therefore, takes a very long time as participant 3 explained further that:

'... it goes from one committee to the next and no one can give you an answer'. (P3, Head Coach, July 2018)

Similarly, participant 1 also stated that:

'The frustration on top of everything else we [elite coaches] need to deal with is that you simply want to continue with the next project or your planning but the decisions are not taken [by $S A R U]$ and no one can tell you where the delay is coming from'. (P1, Head Coach, July 2018)

Participant 1 added that these delays are often as a result of the 'red tape' of SARU as:

'... the fact is that the structure [of SARU] is of such a nature that to make decisions it needs to go through a number of processes'. (P1, Head Coach, July 2018)

This situation often wastes time and money as well as creates confusion and frustration amongst coaches, for example, relating to financial resources, as participant 6 stated:

'I don't understand how it [the budget at SARU] works?' (P6, Head Coach, August 2018)

Participant 1 added that one particular leadership challenge to him is that coaches are not allowed to spend their budgets prior to obtaining approval from SARU first. This causes delays and significantly impacts how he is able to execute important tasks:

'Like every small thing first needs to be approved [by SARU] and as a result we constantly need to ask for permission first to spend our own budgets, then you get it [what you requested permission to purchase] too late so you don't need it anymore by the time you get it'. (P1, Head Coach, July 2018)

In line with this statement, participant 3 stated that 'a fish rots from its head downwards' (P3, Head Coach, July 2018) in reference to SARU's structures and processes. Interestingly, only those coaches who were directly employed by SARU had indicated that they were unable to spend their budgets before obtaining approval to do so, as this was not the case amongst the other coaches who were directly employed by their unions.

In addition to the structure and difficulties related to gaining approval before spending their budgets, the coaches added that they believed that past financial mismanagement within SARU had been the main cause of these measures as it had led to general a lack of available funds at SARU. Participant 3 stated in this regard that:
'There are truly serious problems in South African rugby on all levels as they [SARU] don't have any money' (P3, Head Coach, July 2018)

Participant 4 added:

'I am sure the company [SARU] would have given us more money if they had it' (P4, Head Coach, August 2018)

Participant 5 indicated that:

'... we don't receive enough funding from SARU'. (P5, Head Coach, August 2018)

Related to these themes, participant 5 gave the impression that SARU and South African rugby as a whole were unprofessional:

'I don't think our rugby is being run professionally at all levels, e.g. the player pool is too large and the money that is being spent, the budget [from $S A R U$ ], needs to be spread to all the unions, including the smaller ones. So we don't have a high performance and professional system here [in South Africa]. For example, if a player doesn't make it here with us at [South African Super rugby team], then he simply goes to the [South African 1st Division Currie Cup team], with all due respect to them'. (P5, Head Coach, August 2018)

Participant 1 also agreed with the aforementioned and indicated that this apparent unprofessionalism caused a lack of cooperation between SARU and elite coaches when it came to coaching players:

'It would be much nicer to work together, for decision making to be made faster and communicated more efficiently [by SARU] in order to professionally prepare a player while also keeping your own job'. (P1, Head Coach, July 2018)

This appeared to have created a disjointed system in South African rugby where self-interest appeared to have become more important than the success of the national team, as participant 6 explained:

'The [South African Super rugby team] coach only cares about his job because he's hired and fired by his own board at his union. It's the same for the [South African Super rugby team] and the [South African Super rugby team] and that's why New Zeeland has it right. Everything that's done there is done for the good of New Zeeland rugby and ensuring that the All Blacks [New Zealand senior national team] are successful. So, everybody knows exactly where they fit in. That's why I feel they [SARU] don't care about the greater good or about Springbok [the national team] rugby. E.g. just look at their [Springbok players] conditioning. Physiologically, I think each one of our Super Rugby franchises is on a different conditioning program, so how do you then get together [as a Springboks team] and play a certain game plan when everybody's conditioned differently?' (P6, Head Coach, August 2018)

The aforementioned environmental challenges had created the impression amongst the coaches that SARU was not focused on ensuring that the national team was successful, as participant 3 stated:

'There is no management [by SARU] and the focus is just on transformation and what everyone can get out for themselves 
which makes it is very difficult for us [as coaches]'. (P3, Head Coach, July 2018)

Participant 1 also responded in a similar manner that:

'I often think we [South African rugby] miss the trick as every guy is just worried about his own little area that he is responsible for and forgets that, ultimately, the main job we all have is to make sure that the Springboks win. Not just my team or the part I am responsible for'. (P1, Head Coach, July 2018)

Participant 1 then alluded to the current political climate in South Africa and how that also posed a challenge to his leadership:

'Obviously transformation is just underneath that [ensuring that the Springboks win], but if the Springboks win then the problems related to transformation will also be solved and make things easier for all of us'. (P1, Head Coach, July 2018)

Participant 5 also referred to the political challenges and influences facing coaches, which, he indicated, elite coaches from other countries do not need to contend with:

'... we have other challenges surrounding players. You know the [political] situation in our country as it currently is' (P5, Head Coach, August 2018)

\section{Participant 3 expressed further:}

'I believe that for any leader, regardless of which field you are in, it is challenging in South Africa right now due to our political conditions. All the coaches in South Africa face the same situation as we essentially sit with a transformation problem. So when people ask me why the All Blacks are so successful I explain to them that if you imposed the same type prescriptions [of transformation] on them [elite New Zealand rugby coaches] you are also going to beat them'. (P3, Head Coach, July 2018)

Another environmental factor that was reported included the current economic conditions in South Africa that had led to progressively smaller budgets at the disposal of the coaches in recent years. With the ever-weakening rand and continued economic decline worsened by the recent global COVID-19 pandemic, several professional players and coaches have subsequently selected to sign more lucrative contracts abroad. This has progressively led to a drain of knowledge, experience and talent each year. Participant 2 noted how challenging this has been for the leadership of coaches:

'It is a huge challenge because at the end of the day, regardless of all the work that I put into a player while standing in the sun for hours and going through an entire pre-season together, that player won't necessarily say at the end of the year that he would want to stay with [South African Super rugby team]'. (P2, Head Coach, July 2018)

\section{Participant 5 also stated that:}

'this [South African player contracts] will always be a challenge for South African coaches because, you know, ultimately it is always about the players themselves, as individuals, what they can get for themselves and not about the teams they play for'. (P5, Head Coach, August 2018)
Another environmental leadership challenge related to how coaches need to manage the impact of the media, as participant 3 explained:

'This morning I had to call a player in who was down about what was written about his performance on social media. This is a problem because anyone can say anything on social media about a player, even if that individual had only played for his 3rd team in high school if he was lucky and knows nothing about rugby at the highest level. That places players under huge pressure and you as a coach need to manage that even if you have very little knowledge or background about that kind of thing yourself'. (P3, Head Coach, July 2018)

Despite most coaches stating that the physical infrastructure and equipment available to them were mostly satisfactory, some of them did indicate that it posed a leadership challenge to them as participant 3 stated:

'We have challenges to ensure that our spectators are safe and that they want to be there [at the stadium] as they ultimately buy the tickets that generates income for the union'. (P3, Head Coach, July 2018)

Each of the environmental challenges was mostly out of the direct control of the coaches; these nevertheless presented significant leadership challenges to coaches and that are in some cases unique to the South African context. Coaches, however, have a higher degree of influence on the challenges indicated in the relationships domain.

\section{The relationships domain}

The relationships domain encompassed the next theme that emerged from data, namely relationships challenges. The subthemes related to this theme included relationships with various key stakeholders such as players, assistant coaches and other members of team management. It also included relationships with the board of directors and the CEOs of their respective unions and SARU. All the coaches explained the importance of maintaining effective relationships with the board of directors at the union as well as at SARU. Nevertheless, some of them experienced this as a major leadership challenge as participant 4 explained:

'They [the SARU board] don't know what we do. They make decisions solely on what they see happens between the four lines on television. So to me the feeling is that if they really wanted to do their jobs well and have sound judgement and decision making abilities, they need to spend time inside our systems to actually see what we do so that it is not only a decision based on whether you, the team or a player achieved success on the field or not'. (P4, Head Coach, August 2018)

In addition to experiencing the SARU board as being uninvolved, some of the coaches also expressed dissatisfaction with their relationship with the $\mathrm{CEO}$, as participant 1 said:

'It is frustrating, as it all stops with the CEO and on many occasions you simply don't receive an answer from him'. (P1, Head Coach, July 2018) 


\section{Participant 6 added:}

'We don't have a direct line to the CEO, and as a coach I am not allowed to present anything to him directly or to the board [of SARU].'

This links with what was referred to earlier in terms of the structures and apparent lack of effective communication, which detrimentally affects the relationships between coaches and SARU. When it came to the sub-theme of player management, the player budget was also one of the most significant challenges indicated by almost all the participants. For example, participant 2 stated that:

'... it [the player budget] is probably our biggest challenge at [South African Super rugby team]' (P2, Head Coach, July 2018)

\section{Participant 4 also explained:}

'I believe that if you have more budget you may retain some of your players for a longer period. We are now busy with player contracting again and it is a case of having to beg, borrow and steal to retain the players you want within your allowed budget'. (P4, Head Coach, August 2018)

Participant 5 also added that they often have to try and convince certain players by any means possible to accept the contracts offered to them in South Africa:

'... we cannot compete with the overseas market' (P5, Head Coach, August 2018)

In addition to the challenge of retaining players based on their financial contracts, managing the expectations of players also posed a unique leadership challenge, particularly as their careers developed and they achieved certain milestones such as being selected for the national team. Participant 4 explained:

'You can only have so many players in your starting line-up, so I think from a leadership point of view a great challenge for me this past season in particular was to manage players and their expectations of where they believe they are and what they then believed they should receive, like being in the starting line up every game or a certain contract, based on where they are in their careers and in their lives. That was a really difficult one'. (P4, Head Coach, August 2018)

In this regard, participant 6 indicated that players need to do more to improve relationships between them and coaches, as he felt that:

'the actual change needs to come from them [the players]. Not from people like us [coaches] who believe in giving them those opportunities, but them actually embracing it'. (P6, Head Coach, August 2018)

Managing players who are diverse in terms of their ethnicity, culture and age in the same team also posed a unique leadership challenge as participant 1 indicated that:

'one of my greatest leadership challenges is bringing together players from different ages and cultural groups together each season in the same team and to get the best out of all of them'. (P1, Head Coach, July 2018)
Participant 2 also stated:

'I think to bring together people from different backgrounds and cultures and to lead them is difficult. You don't always know what you shouldn't say. So the challenge is about how to motivate everyone and to keep everyone positive. I have also coached in other countries and I think that it is a huge thing here in South Africa. That, and the fact that I believe we [South African rugby] don't handle success very well" (P2, Head Coach, July 2018)

This was an aspect also mentioned by participant 4 that:

'... in South Africa we don't manage success well and struggle to be consistent once we achieved it'. (P4, Head Coach, August 2018)

As such, understanding and supporting players to be consistent posed a major challenge for coaches and they sometimes did not know how to do this effectively, for example, with off-field challenges as indicated by participant 2, who stated that:

'... the challenge is to get players to understand how to draw the line from rugby, the process of rugby and what you should be able to do to draw this through into your own life, it is not always clear how to bring that across'. (P2, Head Coach, July 2018)

Participant 4 also indicated that sport psychologists are particularly underutilised to assist with these challenges, as he explained that:

'... we underestimate the importance of a psychologist and from a psychology point of view the value of sport psychology in South African sport'. (P4, Head Coach, July 2018)

In terms of supporting players, especially with off-fieldrelated challenges, coaches therefore often feel ill-equipped and participant 5 stated that despite this:

'... there are not really a lot of teams who make use of these guys [psychologists]'. (P5, Head Coach, August 2018)

In addition to the challenges of managing players, the subtheme of managing relationships with team management also posed certain challenges. Given their close working relationships, assistant coaches in particular play a critical role in this respect, which can also pose a leadership challenge to coaches as participant 4 indicated:

'It [relationships with assistant coaches] needs to be of such a nature that you can be honest with one another and speak up if you don't agree with something or believe that it will be to the teams' detriment. So he needs to share his opinion but he needs to do so in a respectful manner, and that needs to go both ways, from me towards him and him towards me. This is however difficult as sometimes coaches are scared to share their opinions, I suppose because they may fear losing their jobs. That is a challenge I continually try to change but it is not easy'. (P4, Head Coach, August 2018)

Amidst these challenges, coaches also at times find it difficult to obtain all of their assistant coaches, who at times have their own ideas and aspirations of becoming head coaches 
themselves, to accept their roles and to 'buy-in' to the head coaches' visions for their teams, as participant 5 stated:

'I believe the biggest leadership challenge is ultimately to get these guys [assistant coaches] to support your philosophy [as head coach]'. (P5, Head Coach, August 2018)

In addition to relationships between coaches and assistant coaches, managing relationships with other members of team management, such as medical staff, can also pose certain leadership challenges. This is because it is not only challenging to identify and appoint the most suitable staff but also to manage potential tensions amongst them, as participant 2 indicated:

'You need to get the right people on the bus and then you need to get them to sit on the right places. Sometimes the staff you have to work with are inexperienced or do not fully understand their roles and your approach to coaching'. (P2, Head Coach, July 2018)

\section{Participant 5 also explained:}

'There is tension sometimes between medical staff and coaches as they [medical staff] have their own ideas about players' readiness to play based on their training, but then, they don't need to tell that player that he is dropped from the team. The biggest leadership challenge therefore is to get everyone aligned [medical staff and coaches] and to work together. Sometimes that is a challenge that needs to work itself out over time'. (P5, Head Coach, August 2018)

In addition to the diverse and complex relationships that coaches need to manage in their roles, they also noted certain challenges of a more personal nature as described in the following section.

\section{The personal domain}

Firstly, a particular personal leadership challenge that emerged was that of a sense of subjective uncertainty about the future, as participant 4 explained:

'So you think, okay, I am the head coach here now, but what is next for me? I finish in [date on which contract expires], but there is not really a career pathway for me, so will my contract be renewed again or where do I go from here?' (P4, Head Coach, August 2018)

In addition to the uncertainty, coaches also subjectively felt that they did not receive inputs from their unions, SARU or from other sources to develop them into better coaches whilst they are in their positions, as participant 5 asked:

'... what does SARU offer coaches to develop them into better coaches? There is nothing. Once you have completed your IRB 1 ,

2 and 3 courses [development courses presented by World Rugby], which is actually a worldwide certificate, there is nothing else'. (P5, Head Coach, August 2018)

Elaborating on this, participant 4 added that he has resorted to try and develop himself through further reading and attending seminars wherever he can. This is, however, difficult because of his full schedule and the demands of his position. Accordingly, he indicated that:
'There is currently no leadership development program for coaches. And if you think about it, one of the most critical factors of being a successful coach at the highest level is your leadership skills and, especially, your people skills. So if they [coaches] can be sent on courses or just implement some kind of program to develop those leadership and people skills to allow them to manage human relationships better, I think that will definitely help'. (P4, Head Coach, August 2018)

Participant 4 indicated that he believed this also contributed to why many coaches from South Africa are only concerned with their own welfare and not with the success of the Springboks, as:

'Every coach is just trying to protect his own interests and wants to be successful because he knows that it is what his job depends on, you know, whether he is going to get fired or not'. (P4, Head Coach, August 2018)

The coaches also indicated that they subjectively experience intense feelings of pressure in their positions. They are finally accountable for what occurs both on and off the field in a sport where there are constant expectations for their teams to win, particularly in South Africa. These results can sometimes mean the end of their own careers, as well as those of their support staff and players. Participant 2 explained that, as a result, he often feels a great deal of pressure and responsibility as:

'If I do my job half-heartedly another person is most likely going to lose his job and, as a result, not be able to care for his wife and children any more. So even if you have a permanent appointment at a union like just printing the tickets, if you do not maintain a certain excellence in your work, everyone is going to suffer. I am always under pressure. As a result I constantly ask myself how I can improve the on field performances of the team so that people keep believing in the leadership I am trying to provide?' (P2, Head Coach, July 2018)

\section{Discussion Outline of results}

It is clear from the results that the participants faced significant and complex leadership challenges. Some are part of the realities of contemporary South African society such as the country's slow economic growth, the weakening rand and political factors like the drive towards transformation. These challenges all form part of the supra-environmental system of South Africa and impact all sectors of its society, including elite rugby. Potential solutions to these challenges fell outside of the scope of the present study, albeit it remained important to note as they nevertheless formed part of the challenges that participants reported and influenced the other domains in which they functioned. Some of them also appeared possible to address, such as those reported in relation to the corporate governance of SARU. Based on the results, it appeared to be inadequate and having a detrimental impact on the participants and the teams they lead. These included apparent bureaucratic 'red tape', which prolonged decision-making processes, coupled with ineffective communication between SARU and coaches. 
These findings were also similar to Orlowski et al. (2016) and Fletcher and Arnold (2011), as the coaches, also reported that uncertainty over their contracts, the responsibilities they held towards those they lead, financial management, staff management, lines of communication, feedback mechanisms, role awareness, organisational and team atmospheres all posed significant leadership challenges to them. Furthermore, the findings also appeared to resemble those by Surujlal and Mafini (2011), as recruitment, selection, training, development, compensation, demographic changes, workforce diversity, changing managerial and coaching skill requirements were also all challenges reported by the participants in the present study. These aspects may be significantly improved without having to invest large amounts of scarce resources through the application of more effective leadership, both from the board and CEO of SARU. In this regard, the transformational leadership style appeared to be best suited as it has been found to be particularly effective in elite sporting environments (Hamza \& Abdelmonem, 2018; Hodge et al., 2014).

Managing relationships with key stakeholders were also identified as a significant challenge in the present study. This was similar to the findings of Thelwell et al. (2010) in that working with other coaches who held conflicting views was also indicated by the participants as a leadership challenge. Interestingly, the emphasis appeared to fall on obtaining more interpersonal skills as opposed to more effective coaching skills per se. As such, it appeared that at the elite level, the emotional intelligence of coaches started to play a more critical role than their actual rugby knowledge and coaching skills.

\section{Practical implications}

From the aforementioned sections, the recommendations made by Surujlal and Mafini (2011) appear to also be applicable in the present study and will, therefore, also be included in the next section.

\section{Limitations and recommendations}

Firstly, with the perception that franchise coaches have more control over their budgets and related aspects than national level coaches and that the latter has less overall autonomy, delegating more authority and control to coaches of national teams, in a similar way to that of most franchise coaches is recommended. This would allow them to make autonomous decisions like their counterparts at the franchises, particularly about their budgets, without having to gain prior approval through sometimes slow and challenging channels. According to the participants, the existing regulations and systems imposed by SARU seem to be sub-optimal as too many stakeholders appear to be included in these processes. This in turn leads to leadership challenges for them within the environmental domain to obtain much-needed support within a timely manner.
Next, it is recommended that existing lines of communication be optimised between SARU and all elite head coaches, along with clarity on all matters affecting the coaches who are in the direct employment of SARU. These matters will include aspects such as career pathway discussions, budget restrictions and other relevant procedures to assist them to become more effective in their roles. A forum is suggested to achieve this on at least two occasions per year where the CEO and relevant executive management can meet with national coaches who are in direct appointment of SARU to discuss and address any possible grievances. When considering that the franchise coaches may have different agendas to meet with SARU, they may not be interested to be included in a forum of this nature. If such a need may arise it is suggested that a separate yet similar forum be arranged for them. Furthermore, the opportunity for the national coaches to have an annual forum to also discuss their experiences with the SARU board will be invaluable to help the Board make decisions which will affect the coaches at coal-face level. This forum can simultaneously also serve as a platform to obtain direct feedback from the CEO and SARU board on matters that are raised. In a similar manner, it is suggested that coaches arrange similar forums with the boards from their respective franchises. If implemented, this can go a long way towards assisting elite coaches to address the leadership challenge within the personal domain of uncertainty regarding their futures. Furthermore, it will also be able to address challenges within the relationships domain by improving their communication and interactions with the CEO and board of SARU.

It is further recommended that clear career pathways and succession planning be implemented for all elite coaches with regular contact sessions between themselves and the CEO of SARU (or their respective franchises) in order to review their performances according to clearly stated key performance indicators depicted in their contracts. Furthermore, it is advised that a clearly structured personal development plan be crafted for every elite coach. It is also advised that any plans to terminate the contracts of elite coaches be communicated to them as far in advance as possible, to allow them to start planning for their careers after their contracts had ended. This will assist elite coaches to address the personal leadership challenge of uncertainty regarding their futures.

The consensus amongst the participants further appeared to be that management styles and systems in general have significant room for improvement on multiple levels throughout South African rugby. According to the authors, adopting a tried and tested leadership model, such as transformational leadership is an example of how these improvements can be achieved. This is because according to the framework by Bass and Avolio (1994), transformational leadership contains four behavioural components, namely idealised influence, inspirational motivation, intellectual stimulation and individualised consideration. Application of this type of leadership style within elite sports domains has 
also been found to effectively increase employee empowerment in multiple sporting codes (Hamza \& Abdelmonem, 2018). As a first step towards implementing such a model, the boards and CEO's of SARU and the respective franchises can begin by communicating a clear vision to all coaches and players that the focus throughout South African rugby should ultimately be to assist the Springboks to be successful.

Since the collection of data for this project, SARU had announced a new form of de-centralised player contracting system with the aim of improving the alignment between the unions and the Springboks (ESPN, 2019). This new model aims to ensure improved collaboration between franchises and SARU to develop so-called 'players of national interest' whilst 'commitment clauses' will also be included in the contracts of newly contracted younger players in an effort to reward them for staying in South Africa (ESPN, 2019). It is believed that this step will right away start to reduce the large number of professionally contracted players in South Africa and from this perspective, be on the right track towards implementing a better high performance system of governance. It will probably also create a more centralised approach towards conditioning of players and implementation of game plans, whilst complimenting the plans of the Springboks head coach by all coaches of other elite South African rugby teams. This can aid coaches with more support and guidance when creating their own conditioning and game plans with the assurance that what they are doing is in line with what is required by the Springboks.

When considering the need for further professional and personal development as was emphasised by the participants, it is proposed that bespoke leadership development packages be designed to equip them with improved leadership, diversity management and EI skills. According to Olawoyin (2018), EI refers to a particular set of skills that enables those who possess it to be optimally 'in touch' with themselves. This, in turn, allows them to interact effectively with others around them, especially in relationships between leaders and followers. This type of package has already been found to be effective within elite sport (Cotterill, 2017; Philippe, Sagar, Gerber, \& Hauw, 2016). It is, therefore, recommended that such a package be made compulsory for all newly appointed elite head and assistant coaches at any elite South African rugby team. It is also advised that they undergo advanced courses on a continuous basis that can further build on these skills at least once a year in accordance with their personal development plans. Finally, it is believed that implementing these recommendations can go a long way towards addressing some of the challenges from all of the domains as highlighted by the participants and, thereby, ensure not only the economic survival, but also the overall leadership improvement of the franchises these coaches lead.

When considering the limitations of the study, the sample size of six participants could be argued to have been small. Furthermore, the study did not emphasise solutions to the challenges raised by participants and also excluded the perspectives of other key stakeholders. As a result of a dearth of research on the topic, limited relevant literature could also be identified, from South Africa and elsewhere. When, however, considering that the total population of the present study consisted of 11 coaches and made use of a qualitative research approach within which smaller numbers of participants are acceptable given that personal experiences are being investigated in-depth, six participants could still have been a sufficiently large sample. Furthermore, the limited amount of identifiable relevant literature was attributed to, amongst other factors, the inability of other researchers to have gained access to this unique population.

\section{Conclusion}

Despite its limitations, the present study succeeded in achieving its objective, which was to gain an in-depth understanding of the leadership challenges experienced by elite South African rugby coaches. As such, it provided valuable contributions on both theoretical and practical levels towards the literature on applied sport psychology and leadership, in particular on leadership amongst a very unique group of leaders, that is, elite South African rugby coaches. Given the lack of other studies on this topic, it is believed that this study was unique in terms of the particular population that was included. It also allowed a number of valuable recommendations to be made by the researchers that, if implemented, could start making a significant contribution towards addressing the challenges highlighted by the participants and allowing South African rugby sides who compete at an international level to remain competitive and economically continue to survive. This appears to be particularly relevant at present with South Africa's economy moving into further decline as a result of, amongst other factors, the global COVID-19 pandemic along with a potential sense of complacency that might have resulted following the country's winning of the rugby world cup in 2019 after this data had been collected. Further research recommendations include conducting similar studies with South African rugby coaches at other non-professional levels, such as schools and clubs. Future studies may also involve board members from SARU and the unions as, similar to head coaches, they are also in key leadership positions and were frequently referred to by the participants in the present study.

\section{Acknowledgements Competing interests}

The authors declare that they have no financial or personal relationships that may have inappropriately influenced them in writing this article.

\section{Authors' contributions}

The results reported here formed part of MBA studies of K.d.P. with J.V. as research supervisor and P.K. as the cosupervisor for the project. 


\section{Funding information}

The authors received no financial support for the research, authorship, and/or publication of this article.

\section{Data availability statement}

The data that support the findings of this study are available on request from the first author. The data are not publicly available because of information contained therein could potentially compromise the privacy of research participants.

\section{Disclaimer}

The views and opinions expressed in this article are those of the authors and do not necessarily reflect the official policy or position of any affiliated agency of the authors.

\section{References}

Arnold, R., Fletcher, D., \& Molyneux, L. (2012). Performance leadership and management in elite sport: Recommendations, advice and suggestions from national performance directors. European Sport Management Quarterly, 12(4), 317-336. Retrieved from https://nwulib.nwu.ac.za/login?url=https://search. ebscohost.com/login.aspx?direct=true \&db=s3h\&AN=78084122\&site=eds-live

Avolio, B.J., \& Yammarino, F.J. (Eds.). (2002). Transformational and charismatic leadership: The road ahead (vol. 2). Amsterdam: JAIElsevierScience.

Bass, B. M., \& Avolio, B.J. (1994). Transformational leadership and organizational culture. International Journal of Public Administration, 17(3-4), 541-554. https:// doi.org/10.1080/01900699408524907

Braun, V., \& Clarke, V. (2006). Using thematic analysis in psychology. Qualitative Research in Psychology, 3(2), 77-101. https://doi.org/10.1191/147808 8706qp063oa

Brown, J.C., Verhagen, E., Viljoen, W., Readhead, C., Van Mechelen, W., Hendricks, S., \& Lambert, M.I. (2012). The incidence and severity of injuries at the 2011 South African Rugby Union (SARU) Youth Week tournaments. South African Journal of Sports Medicine, 24(2) 49-54, https://doi.org/10.17159/2078-516X/2012/v24i2a345

Carmichael, F., McHalle, I., \& Thomas, D. (2010). Maintaining market position: Team performance, revenue and wage expenditure in the English Premier League. performance, revenue and war
Bulletin of Economic Research, 63(4), 464-479. https://doi.org/10.1111/j.1467Bulletin of Economic
$8586.2009 .00340 . x$

Challenge. (2018). In Cambridge Dictionary. Retrieved from https://dictionary. cambridge.org/dictionary/english/challenge

Cotterill, S. (2017). Developing leadership skills in sport: A case study of elite cricketers Case Studies in Sport \& Exercise Psychology, 1(1), 16-25. Retrieved from https:// nwulib.nwu.ac.za/login?url=https://search.ebscohost.com/login.aspx?direct=tru $\mathrm{e} \& \mathrm{db}=\mathrm{s} 3 \mathrm{~h} \& A \mathrm{~N}=122475536 \&$ site $=$ eds-live

Cruickshank, A., \& Collins, D. (2012). Change management: The case of the elite sport performance team. Journal of Change Management, 12(2), 209-229. https://doi. org/10.1080/14697017.2011.632379

Creswell, J. (2009). Research design: Qualitative, quantitative, and mixed methods approaches (3rd edn.). Thousand Oaks, CA: Sage Publications.

Du Plooy, K. (2019). Leadership challenges experienced by elite South African rugby coaches, Master's dissertation, North-West University, Potchefstroom.

Devers, K.J., \& Frankel, R.M. (2000). Study design in qualitative research - 2: Sampling and data collection strategies. Education for health, 13(2), 263-271. https://doi. org/10.1080/13576280050074543

ESPN. (2019). SA Rugby announces de-centralised player contracting model. Retrieved from https://africa.espn.com/rugby/story//id/26939878/sa-rugby-announcesde-centralised-player-contracting-model

Fletcher, D., \& Arnold, R. (2011). A qualitative study of performance leadership and management in elite sport. Journal of Applied Sport Psychology, 23(2), 223-242. https://doi.org/10.1080/10413200.2011.559184

Fletcher, D., \& Arnold, R. (2011). A qualitative study of performance leadership and management in elite sport. Journal of Applied Sport Psychology, 23(2), 223-242. https://doi.org/10.1080/10413200.2011.559184
Fouché, C.B., \& Schurink, W. (2011). Qualitative research designs. In A.S. De Vos, C.B. Fouché, \& C.S. Delport (Eds.), Research at grass roots: For the social sciences and human service professions (4th edn., pp. 312-317). Pretoria: Van Schaik.

Germain, M.L. (2012). Traits and skills theories as the nexus between leadership and expertise: Reality or fallacy? Performance Improvement, 51(5), 32-39. https://doi. org/10.1002/pfi.21265

Goldberg, H., \& Goldberg, I. (2008). Family Therapy (7th edn.). Belmont, MA: Thomson Brooks/Cole.

Greenwood, D., Davids, K., \& Renshaw, I. (2012) 'How elite coaches' experientia knowledge might enhance empirical research on sport performance', International Journal of Sports Science \& Coaching, 7(2), 411-422. Retrived from https:// nwulib.nwu.ac.za/login?url=https://search.ebscohost.com/login.aspx?direct=tru $e \& d b=e o a h \& A N=27855137$

Hamza, A., \& Abdelmonem, M. (2018). The relationship between transformational eadership and employee empowerment in certain Egyptian sports federations. Ovidius University Annals, Series Physical Education \& Sport/Science, Movement \& Health, 18(2), 119-124. Retrieved from https://nwulib.nwu.ac.za/ login?url=https://search.ebscohost.com/login.aspx? direct=true\&db=s3h\&AN=1 30442227\&site=eds-live

Hodge, K., Henry, G., \& Smith, W. (2014). A case study of excellence in elite sport: Motivational climate in a world champion team. Sport Psychologist, 28(1), 60-74. https://doi.org./10.1123/tsp.2013-0037

Jian, G., \& Fairhurst, G.T. (2017). Leadership in organizations. In C.R. Scott \& L. Lewis (Eds.), The international encyclopedia of organizational communication (pp. 1-20). Boston, MA: John Wiley.

Krefting, L. (1991). Rigor in qualitative research: The assessment of trustworthiness. The American Journal of Occupational Therapy, 45(3), 1-19. https://doi. org/10.5014/ajot.45.3.214

Mason, M. (2010). Sample size and saturation in PhD studies using qualitative interviews. Forum Qualitative Sozialforschung/Forum: Qualitative Social Research, 11(3), Art. 8. http://dx.doi.org/10.17169/fqs-11.3.1428

Morgan, M. (2002). 'Optimizing the structure of elite competitions in professional sport - Lessons from Rugby Union', Managing Leisure, 7(1), 41-60. Retrieved from https://nwulib.nwu.ac.za/login?url=https://search.ebscohost.com/login.asp

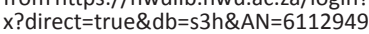

Olawoyin, R. (2018). Emotional intelligence: Assessing its importance in safety leadership. Professional Safety, 63(8), 41-47. Retrieved from https://nwulib.nwu. ac.za/login?url=https://search.ebscohost.com/login.aspx?direct=true\&db=eih\&A ac.za/login?url=https://search

Orlowski, J., Wicker, P., \& Breuer, C. (2016). Determinants of labour migration of elite sport coaches. European Journal of Sport Science, 16(6), 711-718. Retrieved from https://nwulib.nwu.ac.za/login?url=https://search.ebscohost.com/login.aspx?dir https://nwulib.nwu.ac.za/login?url=https://search.e

Pelser-Carstens, V., Keyser, E., \& Surujlal, J. (2015). Relationship between social contract, anxiety, performance, workload and intention to quit among professional sport coaches. African Journal for Physical, Health Education, Recreation \& Dance, 21(3:2), 1009-1023.

Philippe, R.A., Sagar, S.S., Gerber, M., \& Hauw, D. (2016). Players' perceptions of coaches'contributions to their mental toughness. International Journal of coaching Science, 10(1), 37-51. Retrieved from https://nwulib.nwu.ac.za/ login?url=https://search.ebscohost.com/login aspx?direct=true\&db=s3h\&AN=11 2950381\&site=eds-live

Roberts, K. (2013). The power of coaching. NZ Rugby World, 160, 90.

Surujlal, J., \& Mafini, C. (2011). Managing professional sports coaches in South Africa: Perceptions of human resource managers in sport organisations. African Journal for Physical, Health Education, Recreation \& Dance, 2(Suppl), 297-313.

Thelwell, R., Weston, N.V., \& Greenlees, I. (2010). Coping with stressors in elite sport: A coach perspective. European Journal of Sport Science, 10(4), 243-253. https:// doi.org/10.1080/17461390903353390

Von Bertalanffy, L. (1972). The history and status of general systems theory (reprint). Academy of Management Journal, 15(4), 407-426. https://doi.org/ 10.5465/255139

Williams, S.J., \& Kendall, L. (2007). Perceptions of elite coaches and sports scientists of the research needs for elite coaching practice. Journal of Sports Sciences, 25(14), 1577-1586. https://doi.org/10.1080/02640410701245550

Woods, S.A., \& West, M.A. (2016). The psychology of work and organisations (2nd edn.). Croatia: Cengage Learning.

World Rugby Year in Review. (2016). A world Rugby annual report. Retrieved from http://publications.worldrugby.org/yearinreview2016/en/96-1

Yukl, G. (2012). Effective leadership behaviour: What we know and what questions need more attention. Academy of Management Perspectives, 26(4), 66-85. https://doi.org/10.5465/amp.2012.0088 